\title{
Multiple inhalers confuse asthma patients
}

\author{
J. van der Palen*, J.J. Klein*, C.L.A. van Herwaarden**, G.A. Zielhuis ${ }^{+}$, E.R. Seydel ${ }^{++}$
}

\begin{abstract}
Multiple inhalers confuse asthma patients. J. van der Palen, J.J. Klein, C.L.A. van Herwaarden, G.A. Zielhuis, E.R. Seydel. (C)ERS Journals Ltd 1999.

ABSTRACT: This study investigated the influence of the use of different types of inhalers on the adequacy of inhalation technique among adult asthmatics. Three hypotheses were tested: first, patients using only one type of inhaler will demonstrate adequate inhalation technique more often than those with two or more types. Secondly, patients using a combination of dry powder inhalers (DPIs) will demonstrate correct inhalation technique more often than those using the combination of a metered dose inhaler (MDI) and a DPI. Thirdly, some inhalers or combinations of inhalers are more prone to erroneous inhalation technique than others.

Adult outpatients with asthma who regularly used inhaled steroid therapy $(n=321)$ participated in the study. The inhalers investigated were MDIs on the one hand, and the DPIs Turbuhaler $\AA$, Diskhaler $\AA$, Cyclohaler $\AA$, Inhaler Ingelheim $\AA$ and Rotahaler $\mathbb{R}$ on the other.

Of 208 adult asthmatics with only one inhaler, $71 \%$ made no inhalation errors versus $61 \%$ of 113 patients with two or more different inhalers. Of patients with a combination of DPIs $68 \%$ performed all essential checklist items correctly, versus $\mathbf{5 4 \%}$ of patients with the combination of "regular" MDI and DPI. Patients using only the Diskhaler $(\mathbb{R})$ made fewest errors.

Whenever possible, only one type of inhaler should be prescribed. If a combination is unavoidable, combinations of DPIs are preferable to MDI and DPI. The Diskhaler seems to be the most foolproof device.

Eur Respir J 1999; 14: 1034-1037.
\end{abstract}

Many papers have reported that the technique of inhaling medicines in patients with obstructive lung diseases is inadequate, with the percentage of patients inhaling effectively ranging $10-85 \%[1-6]$. Various aspects of inhalation technique have been investigated, from the influence of the type of inhaler [1,7-9] to that of patient characteristics such as age, sex, educational level and diagnosis $[1,4,10,11]$ on the number of errors made. To the authors' knowledge, however, no study has investigated the influence of the use of multiple types of inhalers on the adequacy of inhalation technique. This is not surprising since, in most countries, the metered-dose inhaler (MDI) has been virtually the only inhaler of choice for many years, and so comparative studies regarding this topic were virtually impossible. Nevertheless, this is an important and growing issue, because increasing use of dry powder inhalers (DPIs) in countries in which MDIs constitute the mainstay of therapy is expected. At present, pharmaceutical companies are trying to penetrate new markets with DPIs, which they think are superior in ease of use to the regular MDI. In patients with chronic obstructive pulmonary disease (COPD), this was found to be true $[1,12]$. Therefore, doctors will be faced with the question as to whether to add a DPI to an existing MDI, leading to the use of multiple types of inhaler, or replace the MDI with a DPI so that the patient will be using one type of inhaler only.

In the Netherlands, DPIs have been extensively used for over $20 \mathrm{yrs}$, but MDIs are also still widely used. In the authors' hospital, $70 \%$ of all medication is delivered by
DPI; the remainder is inhaled via MDI. Very few patients are prescribed two different types of MDI (e.g. "regular"

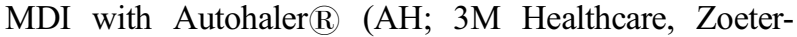
woude, the Netherlands)). Although MDIs from various pharmaceutical companies, with the exception of the AH a breath-actuated MDI, are similar as far as inhalation technique is concerned, DPIs come in many different shapes and sizes. For all of these inhalers, a different technique is required to load the device, prior to inhalation. From previous studies in the authors' department, it is clear that loading these different DPIs is, especially, prone to serious errors $[1,12]$. This has also been observed in other studies [7,9]. This would argue for the prescription of one type of inhaler only, since patients might be confused by different inhalers which need to be handled differently.

This paper addresses the question as to whether asthma patients with more than one type of inhaler are more prone to errors in inhalation technique than those with only one inhaler, as suggested by experience in the authors' outpatient department.

\section{Methods}

Informed consent was obtained from 321 adult outpatients with asthma who were invited to participate in a self-management programme. They all met the inclusion criteria, i.e. aged 18-65 yrs, moderate-to-severe asthma and a minimum prescribed daily dose of inhaled steroids of $200 \mu \mathrm{g}$ beclomethasone (MDI equivalent).

The inhalers investigated were MDIs on the one hand (the "regular" MDI and the AH), and the DPIs Turbuhaler $\AA$ 
(TH; AstraZeneca, London, UK), Diskhaler $(\mathrm{DH}$; GlaxoWellcome, Greenford, UK), Cyclohaler $\mathbb{R}$ ( $\mathrm{CH}$; Pharmachemie, Haarlem, the Netherlands), Inhaler Ingelheim $\mathbb{R}$ (II) and Rotahaler $\mathbb{R}$ (RH; Boehringer Ingelheim am Rhein, Germany) on the other.

A well-trained lung function technician, using inhalerspecific checklists adapted from the checklists of the Dutch Asthma Foundation (table 1), assessed the patients' inhalation technique with the inhalers that they had been using daily for a period of at least a few months to many years. These patients had only received routine inhalation instruction in previous years if their chest physician thought this was necessary. For each inhaler, items essential to the delivery of active drug into the lungs were identified. These key items involve preparing or loading the device prior to inhalation, which is performed differently for all inhalers, and the inspiration manoeuvre. DPIs require a deep and forceful inhalation, whereas for the MDI, a slow continuous inhalation, which should not be halted when the medicine is fired into the mouth, is required. With the "regular" MDI, hand/lung coordination (item 6) is a wellknown problem, which does not exist with the AH; however, raising the lever to the vertical position is crucial to the latter (table 1). When errors are made regarding these key actions, it is likely that no or only an insignificant amount of medicine will be inhaled.

\section{Statistical analysis}

For the purpose of statistical analysis, educational achievement was divided into low-, medium- and highlevel education, based on the Dutch school system. The percentage of patients correctly completing each item on the checklist was calculated for each of the seven inhalers and is presented in table 1 .

Differences in the proportion of patients inhaling correctly, between those with one type and those with more than one type of inhaler, and between those using a combination of DPIs and those using a combination of MDI and DPI, were analysed by means of the Chi-squared test. For the analysis of differences in the percentage of patients with correct inhalation technique between inhalers or combinations of inhalers, only those inhalers were included that were used by $>10$ patients. This resulted in the removal of the $\mathrm{AH}, \mathrm{CH}$ and II as single inhalers, as well as all combinations in which they were used. For the remaining inhalers ("regular" MDI, DH, RH and TH), all possible combinations of two inhalers were available for analysis. For these four inhalers and their combinations the percentage of patients completing all essential items correctly was calculated. In order to adjust for differences in demographic variables (age, sex and educational level) between patients using the various types of inhaler, logistic regression was used to analyse differences among inhalers in the percentage of patients with a perfect inhalation technique.

\section{Results}

In 321 asthmatic patients (mean \pm SD age $43.0 \pm 12.2 \mathrm{yrs}$ ) inhalation technique was assessed. Of these, 148 (46\%) were males and $104(32 \%)$ had received low-level, 119 (37\%) middle-level and 98 (31\%) high-level education. Two hundred and eight patients used one inhaler only, whereas 113 were using more than one type of inhaler. The DH was used by 66 patients, the RH by 54 , the MDI by 50 , the $\mathrm{TH}$ by 26 , the $\mathrm{CH}$ by seven, the $\mathrm{AH}$ by three, and the II by two. The combinations $\mathrm{DH}+\mathrm{RH}, \mathrm{MDI}+\mathrm{TH}, \mathrm{MDI}+\mathrm{DH}$, $\mathrm{MDI}+\mathrm{RH}, \mathrm{DH}+\mathrm{TH}$ and $\mathrm{RH}+\mathrm{TH}$ were used by $21,15,12$, 12,11 and 11 patients, respectively. The number of patients using each of the other combinations was less than five.

Individual item scores for all inhalers are reproduced in table 1 . Two hundred and seventeen $(67.6 \%)$ patients made no errors regarding essential inhalation manoeuvres with their inhaler or combination of inhalers.

Table 1. - Percentage of patients performing the different inhalation manoeuvres instructions correctly*

\begin{tabular}{|c|c|c|c|c|c|c|c|}
\hline & MDI & $\mathrm{AH}$ & $\mathrm{CH}$ & DH & II & RH & TH \\
\hline Shake the inhaler & $86^{*}$ & $75^{*}$ & & & & & \\
\hline Hold inhaler upright & 100 & 100 & 100 & & & $68^{*}$ & $71^{*}$ \\
\hline Open inhaler & & & 100 & & 80 & & \\
\hline Insert capsule & & & 100 & & 100 & 98 & \\
\hline Close inhaler & & & 90 & & 100 & & \\
\hline Hold inhaler horizontal & & & & & & 81 & \\
\hline Raise lever to vertical position & & $100 *$ & & & & & \\
\hline Perforate capsule & & & $100^{*}$ & & $100 *$ & & \\
\hline Perforate blister & & & & $98^{*}$ & & & \\
\hline Rotate both ends to open capsule & & & & & & $98^{*}$ & \\
\hline Rotate grip and back until "Click" & & & & & & & $98^{*}$ \\
\hline Exhale to residual volume & 72 & 75 & 60 & 72 & 88 & 47 & 62 \\
\hline Exhale away from mouthpiece & & & 90 & 91 & 100 & 91 & 93 \\
\hline Keep head upright or slightly tilted & 93 & 100 & & & & & \\
\hline Mouthpiece between teeth and lips & 93 & 100 & 100 & 93 & 100 & 96 & 98 \\
\hline Inhale slowly and press canister & $72 *$ & & & & & & \\
\hline Inhale slowly & & $100^{*}$ & & & & & \\
\hline Inhale forcefully and deeply & & & $100^{*}$ & $91^{*}$ & $100 *$ & $93^{*}$ & $98^{*}$ \\
\hline Continue slow and deep inhalation & $91^{*}$ & $50 *$ & & & & & \\
\hline Hold breath for $5 \mathrm{~s}$ & 85 & 100 & 70 & 84 & 100 & 66 & 83 \\
\hline Exhale away from mouthpiece & & & 90 & 98 & 100 & 92 & 98 \\
\hline Rotate disc & & & & 90 & & & \\
\hline
\end{tabular}

*: essential checklist items. MDI: metered dose inhaler; AH: Autohaler; CH: Cyclohaler; DH: Diskhaler; II: Inhaler Ingelheim; RH: Rotahaler; TH: Turbuhaler. 
Of the 208 patients with only one type of inhaler, 148 (71\%) showed perfect inhalation technique as far as key items were concerned. One hundred and thirteen patients used multiple types of inhalers. Ninety-seven patients used two different inhalers, of whom 63 (65\%) made no errors, whereas for the 14 patients with three inhalers this figure was only $36 \%$. Two patients had to operate four different types, and one of them could demonstrate perfect inhalation technique with all of them. For statistical analysis, patients with two, three and four inhalers were analysed as one group. Sixty-nine $(61 \%)$ patients with more than one inhaler made no errors. The difference from those with only one type of inhaler is $10 \%(95 \%$ confidence interval (CI) $-0.8-21 \%$ ).

Sixty-two patients used a combination of DPIs, whereas 50 were prescribed the combination of a "regular" MDI with a DPI. Of the former group, 42 (68\%) performed all essential checklist items correctly, whereas, of the latter, 27 $(54 \%)$ demonstrated perfect inhalation. The difference was $14 \%$ (95\% CI $-4 \%-32 \%)$.

Almost $91 \%$ of patients with only the DH demonstrated perfect inhalation technique, whereas for patients with the combination of RH and MDI this figure was 33\% (fig. 1). Corrected for differences in age, sex and educational level in a multiple logistic regression model, the differences between patients using only the DH and patients using only the TH, RH or MDI were significant (all $\mathrm{p} \leq 0.01$ ). Also the differences between patients using only the $\mathrm{DH}$ and patients using the combinations $\mathrm{DH}+\mathrm{TH}, \mathrm{RH}+\mathrm{TH}$ and $\mathrm{RH}+\mathrm{MDI}$ were significant. Finally patients using the combination of $\mathrm{DH}+\mathrm{RH}$ performed significantly better than those with the combinations $\mathrm{RH}+\mathrm{TH}$ and $\mathrm{RH}+\mathrm{MDI}$ (both $\mathrm{p}<0.02$ ).

\section{Discussion}

The use of one single type of inhaler seems to be preferable, although the difference compared to patients using more than one type is small. The fact that patients with three different types of inhalers inhale even worse than those with two inhalers, supports this conclusion, but the number of patients in the former category is small. In

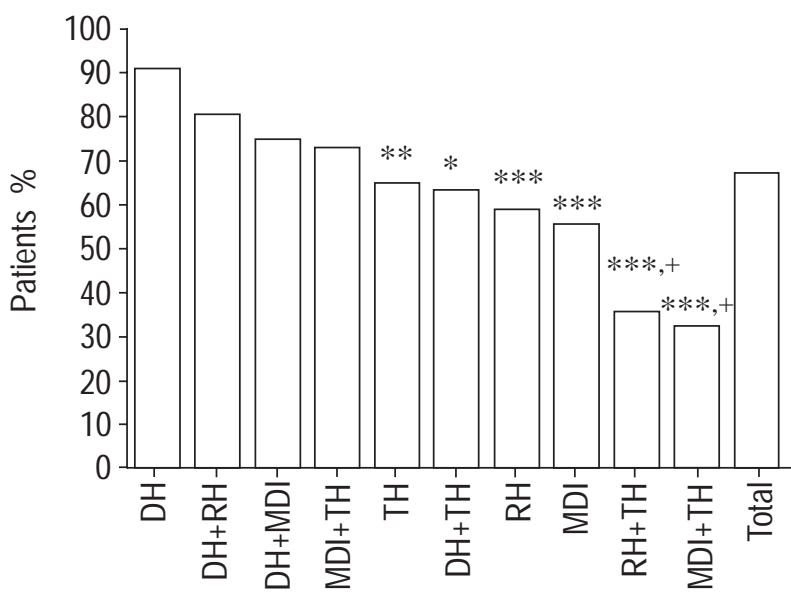

Fig. 1. - Percentage of patients with a $100 \%$ score for essential check list items. DH: Diskhaler; RH: Rotahaler; MDI: metered-dose inhaler; TH: Turbuhaler. *: $\mathrm{p}<0.05, * *: \mathrm{p}<0.01, * * *: \mathrm{p}<0.001$ versus $\mathrm{DH} ;{ }^{+}$: $\mathrm{p}<0.05$ versus $\mathrm{DH}+\mathrm{RH}$. the Netherlands, it is possible for asthma patients to use only one type of DPI for almost all inhaled medication. Both GlaxoWellcome (Diskhaler and Diskus $\mathbb{R}$ ) and Astra (Turbuhaler) have short-acting and long-acting $\beta_{2}$-agonists, as well as inhaled steroids, in the same type of DPI.

Although not statistically significant, patients using a combination of DPIs seemed to be less prone to errors than those using the combination of MDI and DPI. The difference (68 versus 54\%) seems relevant. The explanation for this finding might be that, when inhaling with a DPI, the patient has to inspire forcefully, whereas with an MDI the inhalation has to be slow. This basic difference might be confusing for patients. Unfortunately, it was not possible to study whether a combination of two different types of MDI would be equally as effective as a combination of DPIs. This issue remains open.

Differences between inhalers or combinations of inhalers were found. The most foolproof device seemed to be the $\mathrm{DH}$, and combination with the $\mathrm{RH}$ also seemed a reasonable choice. Only the combinations RH+MDI and $\mathrm{RH}+\mathrm{TH}$ seemed to be poor choices, but the relatively small number of patients using these combinations should lead to cautious interpretation of the present results. Because the $\mathrm{RH}$ is an "old" device, it is not promoted any more, and therefore combinations with the $\mathrm{RH}$ are probably not relevant in countries in which DPIs have been introduced. In the Netherlands, other inhalers are increasingly replacing the RH, because new formulations such as salmeterol and fluticasone propionate are not available in the $\mathrm{RH}$.

The observed differences among inhalers are not easy to compare with the results of other studies, because the method of assessment of inhalation technique differs among studies and the inhalers under investigation are not the same either. In this study, it has been shown that the type of inhaler or combination of inhalers is related to the ability to inhale the medication correctly. The authors have previously assessed inhalation technique in two large groups of patients, using the same checklists for the same inhalers. The first group consisted of 123 patients with COPD, with a mean age of 64 yrs [12]. The percentage of patients who performed all essential checklist items correctly was $42 \%$. For the MDI, DH, RH and TH this was $32,86,35$ and $46 \%$, respectively. The second group involved 152 other patients with COPD with a mean age of 55 yrs. Also in this study, similar differences among inhalers were found. In this group, $60 \%$ made no errors regarding key inhalation manoeuvres and the percentage of patients performing all essential checklist items correctly was 24,96 , 59 and $61 \%$ for the MDI, DH, RH and TH, respectively. The asthmatic patients in the present study (mean age 43 yrs), inhaled better than both groups of patients with COPD, with two-thirds of all patients inhaling correctly. The same pattern among inhalers was observed, although the MDI seemed to be handled relatively better in the present group of asthmatic patients. Increasing age might partly explain the decreased ability to inhale medication correctly. It should be noted, however, that, after the first study [12] inhalation instruction increasingly became standard practice in the authors' departartment, which could explain part of the observed differences.

Another aspect that should not be overlooked is confounding by indication. This would occur, if doctors selectively prescribed certain inhalers to specific types of patient. An example of this might be that, when patients are 
considered to have poor dexterity, doctors might not prescribe the DH because changing the disks, containing the medicine, might be viewed as problematic. However, this is also true of the $\mathrm{RH}, \mathrm{CH}$ and II, for which small capsules of medication have to be handled. For patients with rheumatoid arthritis, firing an MDI, raising the lever of the AH or twisting the Turbuhaler grip might also prove difficult. When patients are physically not able to operate their inhaler correctly, this should not be seen as a flaw in the device, but rather as a judgement error by the prescribing physician. Furthermore, because adjustment for differences in age, sex and educational level did not change the results much, the problem of confounding by indication is not thought to be of sufficient magnitude to explain the observed differences.

With respect to the quality of the measurement of inhalation technique, APPEL [11] has shown that a trained bystander can achieve a $98 \%$ success rate in predicting a significant bronchodilator response from the subject's inhalation technique. This supports the validity of the present study.

Only $68 \%$ of patients succeeded in performing all key manoeuvres correctly. Thus, in one-third of all patients, it is doubtful that the correct dose of medication, if any, is inhaled! Two studies found significantly less bronchodilation in patients who made inhalation errors with an MDI $[11,13]$. Because of faulty inhalation, patients will receive less than optimal benefit from their therapy. This can have a number of consequences. First, the patient will not inhale enough medicine and thus the therapy will appear inadequate. Together with the already existing apprehension regarding steroids, this could lead to noncompliance. In the event of a fast-onset exacerbation of asthma, inadequate inhalation technique might be life-threatening. Secondly, there will be a tendency on the part of the clinician to either prescribe a higher dose or add other drugs (e.g. prednisolone) to the patient's existing regimen, or both, with all the concomitant risks of increased side-effects and overdose. Thirdly, it is possible that the disease is under control but with a dosage of medicines that is far too high because of ineffective inhaler use.

Apart from the therapeutic aspects, there are also economic consequences of poor inhalation technique and thus of poor inhaler design. Unnecessarily high doses and polypharmacy generate higher costs for drugs. More frequent visits to the doctor, possibly followed by admissions because of ineffective outpatient self-treatment, all add to the direct costs of healthcare, and the loss of man-hours and payment of sickness benefit also inflate indirect costs.

Finally, there is the issue of therapeutic ratio. The MDI with the addition of a holding chamber is the only device that improves the ratio of effects and side-effects, by considerably reducing the dose deposited in the mouth and throat. This is particularly important with inhaled corticosteroids. Newman et al. [14] showed that $56 \%$ of particles remained in the holding chamber, with concurrently a lung deposition that was comparable with most DPIs. Therefore, in adult asthma patients susceptible to the sideeffects of inhaled corticosteroids, such as thrush, hoarseness, and bruising of the skin, the choice of an MDI with a holding chamber is a sensible one. Conversely, many patients will probably not experience these side-effects, if they rinse their mouth following steroid inhalation.
In conclusion, many patients with asthma use their inhaler ineffectively. Whenever possible, only one type of inhaler should be prescribed, of which the Diskhaler seems to be the most foolproof device. If a combination is unavoidable, combinations of dry powder inhalers are preferable to metered-dose inhaler plus powder inhaler, but the evidence for this is not overwhelming and more studies should be carried out before any firm conclusions regarding these combinations can be drawn. Finally, for patients using dry powder inhalers, who experience side-effects caused by inhaled steroids despite good inhalation technique and rinsing of the mouth, a metered-dose inhaler with a holding chamber is recommended.

Acknowledgements. The authors are indebted to the pulmonary function technicians, chest physicians and clerical staff of the Dept of Pulmonary Medicine (Medisch Spectrum Twente, Enschede), who did so much to bring this work to a successful conclusion.

\section{References}

1. van der Palen J, Klein JJ, Kerkhoff AHM, van Herwaarden CLA. Evaluation of the effectiveness of four different inhalers in patients with Chronic Obstructive Pulmonary Disease. Thorax 1995; 50: 1183-1187.

2. Manzella BA, Brooks CM, Richards JM, Windsor RA, Soong S, Bailey WC. Assessing the use of metered dose inhalers by adults with asthma. J Asthma 1989; 26: 223230 .

3. Thompson J, Irvine T, Grathwohl K, Roth B. Misuse of metered-dose inhalers in hospitalized patients. Chest 1994; 105: 715-717.

4. Epstein SW, Manning CPR, Ashley MJ, Corey PN. Survey of the clinical use of pressurized aerosol inhalers. Can Med Ass J 1979; 120: 813-816.

5. Epstein SW, Parsons JE, Corey PN, Worsley GH, Reilly PA. A comparison of three means of pressurized aerosol inhaler use. Am Rev Respir Dis 1983; 128: 253-255.

6. Crompton GK. Problems patients have using pressurized aerosol inhalers. Eur JRespir Dis 1982; Suppl 63, 101-104.

7. Brown PH, Lenney J, Armstrong S, Ning ACWS, Crompton GK. Breath-actuated inhalers in chronic asthma: comparison of Diskhaler and Turbuhaler for delivery of beta-agonists. Eur Respir J 1992; 5: 1143-1145.

8. Dekker FW, Kaptein AA, van der Waart MAC, Gill K. Quality of self-care of patients with asthma. J Asthma 1992; 29: 203-208.

9. Anani A, Higgins AJ, Crompton GK. Breath-actuated inhalers: comparison of terbutaline Turbohaler with salbutamol rotahaler. Eur Respir J 1989; 2: 640-642.

10. De Blaquiere P, Christensen DB, Carter WB, Martin TR. Use and misuse of Metered-dose inhalers by patients with chronic lung disease. Am Rev Respir Dis 1989; 140: 910-916.

11. Appel D. Faulty use of canister nebulizers for asthma. $J$ Fam Pract 1982; 14: 1135-1139.

12. van der Palen J, Klein JJ, Kerkhoff AHM. Matige techniek bij het gebruik van inhalatiemedicatie door patiënten met chronische bronchitis/longemfyseem. Ned Tijdschr Geneeskd 1994; 138: 1417-1422.

13. Lindgren S, Bake B, Larsson S. Clinical consequences of inadequate inhalation technique in asthma therapy. Eur $J$ Respir Dis 1987; 70: 93-98.

14. Newman SP, Millar AB, Lennard-Jones TR, Morén F, Clarke SW. Improvement of pressurised aerosol deposition with Nebuhaler spacer device. Thorax 1984; 39: 935-941. 